\title{
A META-ANALYSIS OF SERIOUS MOBILE GAMES TO SUPPORT MUSEUM'S INFORMAL EDUCATIONAL
}

\author{
Meng Wang and Miguel Baptista Nunes ${ }^{1}$ \\ School of Information Management, Sun Yat-Sen University, China
}

\begin{abstract}
This paper uses a meta-analysis approach to explore the state-of-the-art of the use of mobile devices to support gamification for informal learning in museum contexts. This study addresses a complex interdisciplinary type of research where information technology is the catalyzer for a complex intersection of museology, information science and educational studies, and aims at helping game designers, museum educators and educational practitioners on their decision making concerning the selection of IoT components of serious mobile games. Specifically, the paper focuses on investigating IoT technological architectures and IoT technological affordances to serve the diversity of functions and features that can be used by different types of games. As a result, this paper presents 5 main categories of IoT technologies used for serious mobile games in museums and illustrates how each type of well-known types of games implements their functions and features through IoT. The paper recommends that for mobile technologies location aware architectures are crucial and the foundation for design and development of exploratory and geolocation serious mobile games for museums.
\end{abstract}

\section{KEYWORDS}

Museum, Informal Learning, Gamification, Serious Games, IoT Technologies, Serious Mobile Devices, Mobile Games

\section{INTRODUCTION}

\begin{abstract}
"Museums are, first and foremost, free-choice learning environments, that is, public institutions for personal learning" (Falk and Dierking, 2008).
\end{abstract}

Museums have long been seen as places that not only display their collections, but also contribute to cultural dissemination, informal education and social memory. As stated by Washburn (1975), "a museum collection is not its only excuse for being". Museums are regarded as informal learning places that can: complement school education; enhance knowledge of history; enable understandings of cultural backgrounds and environments; enrich awareness of natural and artificial surroundings (Efird, 2014, Akamca et al., 2017). Different types of museums display different exhibitions with different learning atmospheres. Researchers have proposed that the visualization, closeness and even manipulation of emulated items displayed in museums are fundamental to visitors' learning processes and have more impact on understanding and knowledge acquisition (Wang and Nunes, 2018; de Rijcke and Beaulieu, 2011). Visiting experiences and close interaction with artefacts, often in a more inclusive environment, are deemed to have a deeper and longer-lasting effect on learning than classrooms and textbooks (Akamca et al., 2017; Kang et al., 2009; Terreni, 2015; Williams, 1996).

According to Wang and Nunes (2018), the educational roles of museums fall into three categories: formal, informal and complementary. This paper focuses on informal learning roles of museums and how these can be supported by mobile serious games (also known in the literature as educational games). Informal learning is a learner-centered and learner-directed process, where the learner has agency over what is being learned, and how it is learned (Eshach, 2006). The process requires reflection and evaluation of the learning, and increases the likelihood that the learning will be used in future (Wang and Nunes, 2018). Gamification of museum visits aiming at reinforcing informal learning has become a hot topic for the development of museums' educational capabilities. Attempts to generate experiential learning based on

\footnotetext{
${ }^{1}$ Corresponding Author
} 
visitor experiences through using mobile serious games has gained momentum both in academic circles and in practitioner environments. Therefore, in recent years, researchers have concentrated on developing museum mobile applications that go beyond the traditional visit guides or pure entertainment, and focus instead on meeting informal learning objectives though serious games. These edutainment applications aim to engage visitors in knowledge acquisition through playful experiences (Rubino et al, 2015). Advances in mobile technology and the Internet of Things (IoT) have also contributed to make serious games technology better suited to facilitate informal learning in the museum space (Jonhson et al, 2015). The study reported in this paper intended to review the state-of-the-art of the use of IoT technologies in the design, application and use of serious mobile games in museums. This paper first investigates the overall use of IoT technologies by serious mobile games aiming at support informal learning through gamification and then matches known types of games against previously identified IoT technologies.

\section{RESEARCH METHODOLOGY AND DESIGN}

\subsection{Research Aim}

This paper aimed at investigating the existing research on gamification supported mobile technology for museum learning and corresponding gamification activities. Moreover, study aimed at identifying the key factors and characteristics of game designs for this type of learning. Finally, based on identified literature review, the study aimed at establishing a framework for gamification design for mobile technologies and museum learning. Therefore, the underlying methodological approach adopted for this study is a combination of systematic literature with a critical meta-analysis review.

\subsection{Research Question and Objectives}

The following research question guided the research design and research process:

1. What types of serious mobile games and IoT technologies provide support for informal learning and enjoyable experiences in museum visits?

According to these research questions the following research objectives were set to:

1. Establish the state-of-the-art of gamification with mobile technology for museum learning.

2. Classify types of games or gamification activities that are supported by mobile technologies for museum learning. Highlight the highest frequency shown type of mobile game for museum learning.

3. Classify modes of mobile technology use in gamification for mobile learning.

\subsection{Research Methodology}

The research design created for this research is based on two-step a meta-analysis in the sense proposed by Wang and Nunes (2019), which consists of a systematic literature review, followed by a critical analysis based on a multi-matrix representation of findings and a conceptual visualization of this complex multidisciplinary area of use of mobile technology to support serious games in museums.

The first step of the research was conducted by following the systematic literature review general strategy proposed by Nunes et.al (2009) and specific protocol suggested by Jesson et al. (2001). The approach adopted consists of the following steps, which were proposed by Nunes et al. (2017):

1. Identification of keywords;

2. Production of search queries;

3. Definition of inclusion and exclusion criteria;

4. Identification of relevant database;

5. Query of databases and selection of relevant documents;

6. Analysis of the dataset selected.

7. Manual Backward and Forward Citation Search.

The second component of the research followed a critical analysis of the papers selected. This critical analysis aims at more than a mere description and synthesis of the existing literature on this research topic (Saunders et al. 2016). Such an approach requires a researcher to extensively search the literature as well as evaluate and criticize the quality and content of that body of knowledge (Booth et. al, 2009). It consists of a 
constructive critical analysis of theoretical propositions, models and frameworks, and includes rejections and acceptance of these different theoretical constructs (Nunes et al. 2017). The final product should be a clear, well-informed and well-argued critical narrative (Wallace and Wray, 2011; Saunders et al, 2016), which should identify seminal works related to the topic of the research, summarize current debate and theoretical propositions, critically analyze these propositions and present a conceptual model based on a synthesis of all of these debates.

\subsubsection{Search Query Construction}

In this research, the term "mobile technology" was operationalized in terms of three agreed synonyms "mobile device", "mobile phone" and "smart phone", which in other more specific researches may have specific and differentiated meaning, but for the purposes of this research were deemed to represent the same conceptualization.

Furthermore, the term "gamification" was interpreted based on its definition and search queries expanded though the use of three of its variants, namely "game", "serious game", "gamified".

Finally, due to the fast developments in the field, many of the papers retrieved addressed areas of augmented reality and virtual reality. These were deliberately excluded from the search.

As a result three generic search queries were created as follows:

1. "smart phone" AND "museum" AND (gamif* \{gamification, gamified\} OR "game" OR "serious game") NOT ("Augmented reality" OR AR OR "Virtual Reality” OR VR);

2. "mobile phone" AND "museum" AND (gamif* \{gamification, gamified\} OR "game" OR "serious game") NOT ("Augmented reality" OR AR OR "Virtual Reality" OR VR);

3. "mobile device" AND "museum" AND (gamif* \{gamification, gamified\} OR "game" OR "serious game") NOT ("Augmented reality" OR AR OR "Virtual Reality” OR VR).

Since a pilot search performed on the Web of Science (WoS) yielded very low numbers of publications in this area, it was decided to use the Google Scholar Hong Kong (https://www.google.com.hk) as the source for this research. The statistics and basic findings for each of the queries are presented in Table 1 in section 3.1 .

\subsubsection{Inclusion and Exclusion Criteria}

There were no date limitations imposed on the findings of the search queries listed above. Although the study is primarily limited to the museum sector, many of the papers retrieved focus on historical places of interest, cultural attractions and cultural heritage institutions, etc. These were also included in the study.

Google Scholar is an inclusive search engine, retrieving papers even if only two of the AND components of the search query were found on the paper. Therefore, during the first reading of titles and abstracts papers were excluded from the study if they were solely technical, the games implemented did not make exclusive use of mobile devices, or the focus of the paper was not on gamification, but on orientation, visit guidance or mobile advertisement of the museum.

\section{SYNTHESIS AND PRESENTATION OF FINDINGS}

\subsection{Descriptive synthesis of findings}

This descriptive synthesis provides a very brief statistical overview of the systematic literature review. Table 1 shows the results of the different searches that composed the systematic review and were submitted to Google Scholar. The three searches had three distinct primary focuses of inquiry on the same context: smart phone, mobile phone and mobile device. All three search queries shared the same exclusion criteria and core keywords. All three searches returned similar numbers of articles in a total of 868 papers. However, as expected from the start there as significant amount of duplication in the final document set (circa 2/3).

After eliminating duplication and then screening the title, keywords, abstracts, which is a selection procedure for doing systematic literature review proposed by Nunes et al., (2017), this study has identified 61 full texts that were eligible for further reading a potential selection for the study. These 61 full papers were read in their entirety and filtered according to further exclusion criteria: (i) mention of mobile devices but no serious game application implemented; (ii) mention of gamification but only as future work; (iii) mention to mobile devices application as future work; (iv) mention of gamification and mobile devices in the same paper but not integrated into one application; and (v) mention of mobile devices and museums (including 
references to cultural information resources), but not gamification. Thus, finally there were 30 full texts identified for full inclusion in the critical review. This is a relatively small number of papers that reflects a small subfield of a complex interdisciplinary research are in the intersection of museology, information science and educational studies.

Table 1. Results distribution for each of the search queries and database

\begin{tabular}{|c|c|c|c|c|}
\hline $\begin{array}{l}\text { Query } \\
\text { Order }\end{array}$ & Search query & $\begin{array}{l}\text { Number of } \\
\text { documents } \\
\text { from Google } \\
\text { Scholar }\end{array}$ & $\begin{array}{l}\text { Relevant } \\
\text { document from } \\
\text { Google Scholar } \\
\text { (title+ abstract) }\end{array}$ & $\begin{array}{l}\text { Relevant } \\
\text { document from } \\
\text { Google Scholar } \\
\text { (full paper) }\end{array}$ \\
\hline 1 & $\begin{array}{l}\text { "smart phone" AND "museum" AND (gamif* \{gamification, } \\
\text { gamified\} OR "game" OR "serious game") NOT } \\
\text { ("Augmented reality" OR AR OR "Virtual Reality" OR VR) }\end{array}$ & 362 & 52 & $15 \times 2$ \\
\hline 2 & $\begin{array}{l}\text { "mobile phone" AND "museum" AND (gamif* } \\
\text { \{gamification, gamified\} OR "game" OR “serious game") } \\
\text { NOT ("Augmented reality" OR AR OR "Virtual Reality" OR } \\
\text { VR) }\end{array}$ & 235 & 46 & 28 \\
\hline 3 & $\begin{array}{l}\text { "mobile device" AND “museum" } \text { AND } \text { (gamif* } \\
\text { \{gamification, gamified\} OR "game” OR “serious game") } \\
\text { NOT ("Augmented reality" OR AR OR "Virtual Reality" OR } \\
\text { VR) }\end{array}$ & 271 & 57 & 18 \\
\hline \multicolumn{2}{|c|}{ Total documents returned } & 868 & & \\
\hline \multicolumn{2}{|c|}{ Total documents after removal of duplicates and not-found articles } & 259 & & \\
\hline \multicolumn{3}{|c|}{ Total number of relevant documents after title, abstract analysis and key words } & 155 & \\
\hline \multicolumn{4}{|c|}{ Total documents of relevant documents after full content analysis } & 61 \\
\hline \multicolumn{4}{|c|}{ Total documents after full content analysis and applying additional exclusion criteria } & 30 \\
\hline \multicolumn{4}{|c|}{ Total documents after manual backward and forward citation search } & 9 \\
\hline \multicolumn{4}{|c|}{ Final total of documents selected for the meta-analysis } & 39 \\
\hline
\end{tabular}

Finally, in order to guarantee that no seminal paper was missed, a manual search was conducted using backward and forward citation analysis as proposed by Nunes et al (2017). This resulted in the addition of 9 ( 3 from backward and 6 from forward citation) extra full papers that were inspected by screening the title, keywords, abstracts and exclusion criteria as explained above. Therefore, the final article data set was composed by 39 full texts, which were subsequently subject to a critical analysis that resulted in the discussion in the next sections.

\subsection{Critical Synthesis of Findings}

\subsubsection{IoT Technological Centered Discussion}

Since this study addresses a complex interdisciplinary type of research where information technology is the catalyzer of a complex intersection of museology, information science and educational studies, the first instinct was to concentrate on technological architectures and technological affordances. In the case of this study the catalyzer is in itself complex formed by a combination of mobile devices and IoT.

Table 2. IoT Technologies for Mobile Serious Games in Museums

\begin{tabular}{|c|c|c|c|}
\hline \multirow[t]{2}{*}{ Individual IoT Technologies } & \multicolumn{2}{|c|}{$\begin{array}{l}\text { Typical Technological } \\
\text { Architectures } \\
\text { for Mobile Games }\end{array}$} & \multirow[t]{2}{*}{ Source } \\
\hline & $\begin{array}{l}\text { Location- } \\
\text { aware } \\
\text { technology }\end{array}$ & $\begin{array}{l}\text { Context- } \\
\text { aware } \\
\text { technology }\end{array}$ & \\
\hline \multicolumn{4}{|l|}{ User Profiling } \\
\hline Authentication & & $\sqrt{ }$ & Kim et al. (2015) \\
\hline Content Personalization & & $\sqrt{ }$ & Stylianidis (2015) \\
\hline Recommender Systems & & $\sqrt{ }$ & $\begin{array}{l}\text { Rosmansyah and Rosyid (2017), } \\
\text { Sweetser and Wyeth (2005), }\end{array}$ \\
\hline \multicolumn{4}{|l|}{ Interaction } \\
\hline $\begin{array}{l}\text { Sharing with others via Social Media (e.g. } \\
\text { Facebook) }\end{array}$ & $\sqrt{ }$ & $\sqrt{ }$ & $\begin{array}{l}\text { Rosmansyah and Rosyid (2017), } \\
\text { Hughes and Moscardo (2017), Russo } \\
\text { et al. (2009). Nilsson et al., (2016). }\end{array}$ \\
\hline $\begin{array}{l}\text { Communicating with others via VOIP (e.g. from } \\
\text { inside the game itself such as points rankings, } \\
\text { points mechanic) }\end{array}$ & $\sqrt{ }$ & $\sqrt{ }$ & Jones et al. (2017) \\
\hline
\end{tabular}




\begin{tabular}{|c|c|c|c|}
\hline Reading others posts and comments & & $\sqrt{ }$ & Jones et al. (2017). \\
\hline $\begin{array}{l}\text { Real-time competition based on a navigation } \\
\text { system (e.g. Interactive guide) }\end{array}$ & $\sqrt{ }$ & & $\begin{array}{l}\text { Kuflik et al. (2011), Jones et al. } \\
\text { (2017). Swacha (2019), Massaty et al } \\
\text { (2017), Chiou (2010). }\end{array}$ \\
\hline \multicolumn{4}{|l|}{ Manipulation of Virtual Artefacts } \\
\hline 3D Models (e.g. Senses of touching) & & $\sqrt{ }$ & $\begin{array}{l}\text { Jones et al. (2017), Rowe et al. } \\
\text { (2014). }\end{array}$ \\
\hline Virtual Reality Models (e.g. Senses of touching) & & $\sqrt{ }$ & $\begin{array}{l}\text { Laine et al. (2007), Jones et al. } \\
(2017) \text {, }\end{array}$ \\
\hline $\begin{array}{lllll}\begin{array}{l}\text { Augmented } \\
\text { touching) }\end{array} & \text { Reality } & \text { Models } & \text { (e.g. Senses } & \text { of } \\
\end{array}$ & & $\sqrt{ }$ & $\begin{array}{l}\text { Froschauer et al (2012), Jones et al. } \\
\text { (2017) }\end{array}$ \\
\hline Mixed Reality Models (e.g. Senses of touching) & & $\sqrt{ }$ & Jones et al. (2017) \\
\hline \multicolumn{4}{|l|}{ Geo-location Information } \\
\hline Near Field Connection (NFC) & $\sqrt{1}$ & $\sqrt{1}$ & Sánchez et al. (2011) \\
\hline Radio frequency identification (RFID) & $\sqrt{ }$ & $\sqrt{ }$ & Sánchez et al. (2011) \\
\hline Quick Reponses (QR) code & $\sqrt{ }$ & $\sqrt{ }$ & $\begin{array}{l}\text { Kristianto, Dela and Santoso (2018), } \\
\text { Fitz-Walter and Tjondronegoro } \\
\text { (2011), Su and Cheng (2013), } \\
\text { Meishar-Tal and Ronen (2016), Rhee } \\
\text { \& Choi, (2015). }\end{array}$ \\
\hline Bar code & $\sqrt{ }$ & $\sqrt{1}$ & Fitz-Walter and Tjondronegoro (2011) \\
\hline Global positioning system (GPS) & $\sqrt{ }$ & $\sqrt{ }$ & $\begin{array}{l}\text { Amato et al, (2013), Greenspan and } \\
\text { Whitson (2013), Chiou (2010), Tal } \\
\text { (2019). }\end{array}$ \\
\hline GPS maps and sensors & $\sqrt{ }$ & $\sqrt{ }$ & $\begin{array}{l}\begin{array}{l}\text { Fitz-Walter and } \\
(2011) .\end{array} \\
\begin{array}{l}\text { Tjondronegoro } \\
\end{array}\end{array}$ \\
\hline Automatic location detection & $\sqrt{1}$ & $\sqrt{ }$ & Stylianidis (2015), Kim et al. (2015) \\
\hline Location detection via QR or RIFD codes & $\sqrt{1}$ & $\sqrt{1}$ & $\begin{array}{l}\text { Tal (2019), Kristianto, Dela and } \\
\text { Santoso (2018), Greenspan and } \\
\text { Whitson (2013). }\end{array}$ \\
\hline Automatic target detection & & $\sqrt{ }$ & $\begin{array}{l}\text { Su and Cheng (2013), Wang et al. } \\
\text { (2017) }\end{array}$ \\
\hline $\begin{array}{l}\text { Target detection via QR or RIFD codes (e.g. Icon/ } \\
\text { sticker, presence of marine animals in detail) }\end{array}$ & & $\sqrt{ }$ & $\begin{array}{l}\text { Su and Cheng (2013), Cesário et al. } \\
\text { (2017), Ballagas and Walz(2007). }\end{array}$ \\
\hline $\begin{array}{l}\text { Target detection using video camera to read bar } \\
\text { code. }\end{array}$ & & $\sqrt{ }$ & Fitz-Walter and Tjondronegoro (2011) \\
\hline \multicolumn{4}{|l|}{ Content Management and Adaptation } \\
\hline $\begin{array}{l}\text { Cloud storage and access (e.g. data base of } \\
\text { introduction information for each historical place) }\end{array}$ & & $\sqrt{ }$ & Kim et al. (2015) \\
\hline $\begin{array}{l}\text { Learning analytics (e.g. actively and free choice } \\
\text { for learning, self-monitoring and reflection, } \\
\text { progressive challenges, immediate feedback) }\end{array}$ & & $\sqrt{ }$ & Rowe et al. (2014), Kim et al. (2015). \\
\hline $\begin{array}{l}\text { Image capture, manipulation and description } \\
\text { (e.g. photographic, video or 3D model) }\end{array}$ & & $\sqrt{ }$ & $\begin{array}{l}\text { Kim et al. (2015); Stylianidis (2015); } \\
\text { Bujari et al.(2017), }\end{array}$ \\
\hline
\end{tabular}

The analysis of the 39 papers selected revealed that there seems to be a developing dichotomy in the design of this type of serious game for museums around the concepts of location aware and context aware technology (Hwang et al., 2011). Most of the papers in the dataset explicitly use one or both of these types of technological architectures. However, the definition and discussion of these could only be found in depth on papers outside the scope of the systematic literature review.

Location aware technologies were initially developed in the 1980s. Early versions of this type of applications relied on location-sensing technologies to determine positions and corresponding surroundings nearby that location (Want and Schilit, 2001; Hazas et al., 2004). However, the services using these early location aware technologies were limited by low accuracy, weak coverage, low frequency of location updates. Moreover, as stated by Kaasinen (2003) location aware services differ considerably from other more traditional mobile services, since they are not just being carried by the user and operated when convenient, but they are actually used on the move and therefore not be the user's primary task that may be the movement itself. This may cause loss of information that is not caused by a weaknesses in the service but because the demands of the physical environment (e.g. background noise, illumination, weather, cross contact with other movers, etc.) may distract user's attention and disturb usage. Finally, one of the early problems with location based systems were the costs of installation and maintenance that at the time were very high (Hazas et al., 2004).

Hwang et al. (2011) use this same argument to justify that before 2010 due to these costs of developing context aware device/ technology and due to the lack of instant support for collaborative discussions, mobile learning applications were mainly based on location factors rather than the context. In fact, concept of context aware technology was firstly proposed in 1994, but the only put into practice in the early 2010 s. 
Context aware systems are predicated on the principle that geographical information by itself does not meet the increased locality information needs of users, but should take the broader contextual information of that location to support users' activities, searches and objectives (Want and Schilit, 2001). Context aware mobile systems respond to this criticism by using context to provide relevant information and services to the user, where relevance depends on the user's task not just geographical location (Dix et al., 2000; Dey, 2001). Hong et al., (2009) pointed out that this very nature of the context aware technologies can provide better services by meeting the user's personal needs based on a combination of physical and personal contexts. However, this is a rather difficult task since as proposed by Kaasinen (2003) in mobile environments all elements of the context of use may vary according to the needs of the different users who are engaged in many different tasks that cannot all be anticipated in the application design. Therefore, context aware technologies extract data from surroundings of a device and present it by analyzing user behaviors or responding explicitly stated requirements (e.g. find me a restaurant) (Gellersen et al., 2002; Byun and Cheverst, 2004).

Having identified the two main types of architectures that can be used in serious mobile games to provide support for informal learning and enjoyable experiences in museum visits, the next step in our critical analysis was to compare and contrast the IoT technologies that support these two architectures (Table 2) and how these IoT technologies are used in different the different types of serious mobile games (Table 3 ). The typology of games used in Table 2 was presented by Wang and Nunes (2019). The IoT technologies referred to in Table 2 are directly related with the features and implementation of the two types of architectures. In-door location aware architectures for instance commonly use radio frequency identification (RFID) tags, whilst out-door (open-air museums) ones use global positioning system (GPS) (Amato et al, 2013; Greenspan and Whitson 2013; Chiou, 2010; Tal, 2019). On the other hand, context aware architectures use quick response codes $(\mathrm{QR})$, recommender systems and semantic web applications (Miyata and Kozuki, 2008; Hwang et al., 2011).

Table 2 focuses on the IoT technologies that have been used in support of gamification applications for museums with an educational purpose. In addition, table 2 provides a mapping and comparison of the use of these IoT technologies for location and context aware architectures.

As shown on table 2, these IoT technologies could be classified into the following 5 main categories: user profiling; interaction; manipulation of virtual artefacts; geo-location information; content management and adaptation.

The first category of user profiling includes the following types of technologies: authentication, content personalization and recommender systems. The major advantage of setting up a user profiling component is customization that is based on the record of users' information seeking and searching behavior. This record is collected as the user engages with the museum collection and employs other user profiles and similarity algorithms to provide personalized information and specific recommendations that may maximize satisfaction of the visiting experience (Kim et al. 2015, Stylianidis 2015, Rosmansyah and Rosyid, 2017, Sweetser and Wyeth, 2005).

The second category of IoT technologies focuses on enhancing visitor's museum experiences by offering an interactive approach. For instance, interaction may happen when the players share their gaming experiences or a specific interest in an artefact in the collection with peer players or even widely on their social media applications (Rosmansyah and Rosyid, 2017, Hughes and Moscardo, 2017, Russo et al., 2009). In addition, interaction may occur if the serious game application includes chat facilities or VOIP function that enable the player to communicate, discuss and comment experiences with the others during the playing activity. These interaction features make full use of common facilitates afforded by the mobile devices (Jones et al., 2017). Moreover, interaction may be achieved through asynchronous facilities that allow the reading previous players' posts and comments (Jones et al., 2017). Finally, interaction may take place through competition and become part of the game design by using external motivation triggers such as points, badges, and leaderboard membership to motivate players and prove their sense of worth and winning and complete the serious game (Jones et al., 2017, Kuflik et al., 2011).

Thirdly, the capacity of manipulation of virtual artefacts is increasingly becoming more realistic and therefore more interesting in terms of artefact visualization, understanding and even providing a sense of touching. This type manipulation requires the support of a particular type of technologies such as 3D visualization, Virtual Reality, Augmented Reality and Mixed Reality (Jones et al., 2017).

One of the most important and significant categories of IoT are geo-location information technologies which also one of the most important affordances of mobile technologies. This type of IoT uses sensors or recognition technologies to capture and identify local positioning information that can be used to navigate, guide, control, re-direct and complete the serious games. These types of IoT ranges from Global positioning system (GPS which is usually only used in outdoors museums, heritage sites and exhibitions) to more 
common Quick Reponses (QR) code reading devices; automatic location detection; automatic target detection; target detection via QR, Radio Frequency Identification (RFID) codes or bar code; target detection using video camera; location detection via QR or RIFD codes. (Kristianto, Dela and Santoso, 2018; Fitz-Walter and Tjondronegoro, 2011; Su and Cheng, 2013; Meishar-Tal and Ronen, 2016). The developments of mobile phones have contributed to the seamless incorporation of these technologies on the devices, such as readers for Near Field Connection (NFC), RFID. These can automatically be used for location and target identification and offer easier operation and access (e.g. no need to open phone camera to scan or read codes) as well as resulting in significant savings in development and extra HW resources when compared with early technologies such as QR and barcode (Sánchez et al., 2011). One successful example of NFC technology used for museum objects detection was described by Cesário et al. (2017) that used stickers for reading with mobile phones to offer information on marine animal's specimens and complemented the existing information on the text tags.

Finally, content management technologies are probably the earliest to have been adopted in this type of application but have been enhanced with the emergence of recent technological developments such as cloud storage and access that has been implemented for storage data and sharing data in a wide variety of aspects, ranging from descriptive information about the artefacts (text, images, video, metadata) to actual user profile and behavioral information (Kim et al., 2015). In addition, Kim et al (2015) stressed that learning analytics plays a role in profiling, customization, content management and recommendation. Moreover, these researchers stated that these content management technologies can be extremely useful for photographic image capture, video, and 3D model manipulation and description (Kim et al., 2015).

\subsubsection{Game Type Centered Discussion}

As part of an earlier research effort, Wang and Nunes (2019) proposed a classification of serious games for informal learning in museums. This classification was a general one, not specifically aiming at IoT mobile gamification, and divided games according to their purpose and features. The study reported in this paper identified a variety of mobile game types used specifically in IoT mobile games that are consistent with the Wang and Nunes (2019) proposition as shown in Table 3. This table illustrates the features and functions of IoT technologies as identified in Table 2 against its use in each of the mobile games types.

As Table 3 shown that out of 13 types of games that compose Wang and Nunes (2009) classification, only 8 types were identified in the current data set. From the 5 types not found, documentary games are the most traditional type. This type of game was very prevalent in non-interactive technologies of the $20^{\text {th }}$ Century, such as video and audio presentations and documentaries. Mobile devices are part of a new generation of ICT devices and provide much more rich interactivity features and it is quite reasonable to expect that this classic type of documentary game is not part of modern IoT mobile game designs. Stimulation and strategy games are also classic types of educational games, but they require long periods of engagement that are not compatible with nowadays relative short visits to museums. This type of game was widely developed for informal learning in the museum in complement to classroom education and are still very successfully used in this type of setting, where the engagement with the museum may imply day visits and even multiple visits. One the other hand, there is not clear reason to justify the absence of role play games or pervasive games. One possible explanation for the absence of role play games is the complexity of the game script necessary to implement multiple roles and corresponding game plots. The design and development of IoT mobile games is still in its infancy and the lack of this type of game may just be due to an early stage of evolution of gamification using this type of technological setting. Similarly, pervasive games are usually associated with Virtual Reality (VR) applications that are still rather inefficiently used by mobile devices.

The meta-analysis of the literature selected shows quite clearly that in relation to the IoT technologies 5 categories identified in Table 3, geo-location IoT technologies are the most used, in fact used by all of the 8 identified types of games. This reflects the optimal use of IoT applications, that is, the use of sensors or tags to identify spaces and artefacts and help in navigating through the museum physical environment while obtaining rich information and detailed explanations. This use of geo-location can therefore stimulate informal learning through discovery, exploration and challenges set around artefacts in disparate locations in the museum. Moreover, apart from the exploration games and adventure games, all other types of games that are supported by geo-location information technologies also used other technologies (i.e. content management and adaptation and interaction) complementarily in order to achieve their purpose and implement game plots. For instance, treasure hunt games set challenges for learners aiming to locate, understand and relate artefacts in disparate locations in the museum. The ocean game designed by Cesário et al (2017) is a point treasure hunt game and challenges players to collect 13 marine species and answer a quiz to gain points and acquire digital badges. In addition, once the player used the mobile device to identify 
the sensor (sticker) that corresponds to a certain marine species, he receives both a written text explanation of that species as well as 3 related curiosity scientific facts. After collecting all 13 marine species, the visitor is presented with a quiz that evaluates players' newly acquired understandings from reading the textual information and curiosity scientific facts for the different species (Radeta et al, 2017; Cesário et al, 2017).

Location based game is the type that uses the highest number (4 out of 5) of the IoT technologies identified in Table 3. In addition, it is also the game type that implements the larger diversity types of functions under these main technologies. Wang and Nunes (2019) proposed that the features of location games are navigation systems combined with informative descriptions and explanations of items in the museum. Navigation features of location games require location detection or target detection through the use of GPS in open air museums (Sedano et al., 2012; Greenspan and Whitson, 2013); of sensors in conventional museums (Heumer et al., 2007); or by scanning the QR code (Hwang et al., 2011; Ceipidor et al., 2009). Modern versions of this type of game draw narratives, explanations, multimedia objects and quizzes related to museum artefacts and/or locations by accessing cloud storage (Kim et al., 2015) and implementing learning analytics for customization and recommendation purposes (Hsu et al., 2018). The combination of these two technologies allows players to make active choices for learning, self-monitor their progress and reflect on the progressive game challenges through immediate feedback. In addition, modern games actively encourage social interaction with other learners and visitors by sharing experiences, scores and even frustations with others via social media, such as Facebook (Machado, 2016; Nilsson et al., 2016; Rosmansyah and Rosyid, 2017).

Table 3. Implemented Mobile Features and Functions by Serious Mobile Games matched against Wang and Nunes (2019) classification

\begin{tabular}{|c|c|c|c|}
\hline Types of Games & & Features and Functions Supported by Mobile Technology & Sources \\
\hline Documentary games & 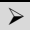 & No mobile phone application found in the selected data set. & \\
\hline $\begin{array}{l}\text { Treasure hunt/Scavenger hunt motif } \\
\text { (Discovering game) }\end{array}$ & $>$ & $\begin{array}{l}\text { Geo-location information } \\
\text { - } \quad \text { GPS maps and sensors } \\
\text { Location detection via QR and RIF codes, } \\
\text { - } \quad \text { Quick response (QR) code, } \\
\text { - Target detection using video camera to read bar code, } \\
\text { Target detection via QR and RIF codes, } \\
\text { Bar code } \\
\text { - } \quad \text { Location detection via QR and RIF codes. } \\
\text { Content management and adaptation } \\
\text { - Cloud storage and access, } \\
\text { Learning analytics. }\end{array}$ & $\begin{array}{l}\text { Kim et al. (2015), Jones et al. (2017), Tal } \\
\text { (2019), Meishar-Tal and Ronen (2016), Fitz- } \\
\text { Walter and Tjondronegoro (2011), Cesário et } \\
\text { al. (2017) }\end{array}$ \\
\hline $\begin{array}{l}\text { Puzzle (Gamified learning activities, } \\
\text { Tasks Games) }\end{array}$ & $>$ & $\begin{array}{l}\text { Geo-location information } \\
\text { - GPS maps and sensors } \\
\text { Content management and adaptation } \\
\text { - Learning analytics } \\
\end{array}$ & Su and Cheng (2013), Cabrera (2005) \\
\hline Trivia (quiz) & $>$ & $\begin{array}{l}\text { User profile } \\
\text { - Content personalization } \\
\text { Geo-location information } \\
\text { - } \quad \text { GPS maps and sensors } \\
\text { Interaction } \\
\text { - } \quad \text { Share with others via social media } \\
\text { Communicating with others via VOIP }\end{array}$ & $\begin{array}{l}\text { Rosmansyah and Rosyid (2017), Ieiri et al. } \\
\text { (2017) }\end{array}$ \\
\hline Mini games & $>$ & $\begin{array}{l}\text { Geo-location information } \\
\text { - GPS maps and sensors } \\
\text { Content management and adaptation } \\
\text { - Learning analytics } \\
\end{array}$ & Stylianidis (2015), \\
\hline $\begin{array}{l}\text { Individual or group task games (Quest } \\
\text { Game) }\end{array}$ & $>$ & $\begin{array}{l}\text { Interaction } \\
\text { - } \quad \text { Real-time competition based on a navigation system }\end{array}$ & Cabrera (2005), Wang et al. (2017) \\
\hline Stimulation games & $>$ & No mobile phone application found in the selected data set. & \\
\hline $\begin{array}{l}\text { Exploration games (Tangible User } \\
\text { Interface (TUI) game/ Discovering } \\
\text { game) }\end{array}$ & $D$ & $\begin{array}{l}\text { Geo-location information } \\
\text { - } \quad \text { Global positioning system (GPS) } \\
\text { - } \quad \text { Location detection via QR and RIF codes, } \\
\text { - } \quad \text { Quick response (QR) code, } \\
\text { - Target detection using video camera to read bar code, } \\
\text { - } \quad \text { Bar code } \\
\text { - } \quad \text { Location detection via QR and RIF codes. }\end{array}$ & $\begin{array}{l}\text { Xhembulla (2014), Kim et al. (2015), Wang } \\
\text { et al. (2017), Sánchez et al. (2011) }\end{array}$ \\
\hline Role play games & $>$ & No mobile phone application found in the selected data set. & \\
\hline Adventure games & $>$ & $\begin{array}{l}\text { Geo-location information } \\
\text { - } \quad \text { Global positioning system (GPS) }\end{array}$ & $\begin{array}{l}\text { Amato et al, (2013), Greenspan and Whitson } \\
\text { (2013), Chiou (2010), Tal (2019). }\end{array}$ \\
\hline Strategy games & $>$ & No mobile phone application found in the selected data set. & \\
\hline Location based games & & $\begin{array}{l}\text { Geo-location information } \\
\text { - } \quad \text { Global positioning system (GPS), } \\
\text { GPS maps and sensors, }\end{array}$ & $\begin{array}{l}\text { Wang et al. (2017), Kristianto et al., (2018), } \\
\text { Greenspan and Whitson (2013), Kim et al. } \\
\text { (2015), Xhembulla (2014), Kim et al. (2015), }\end{array}$ \\
\hline
\end{tabular}




\begin{tabular}{|c|c|c|}
\hline & $\begin{array}{l}\text { - } \text { Quick response }(\mathrm{QR}) \text { code, } \\
\text { - } \quad \text { Location detection via QR and RIF codes, } \\
\text { Target detection using video camera to read bar code, } \\
\text { - } \quad \text { Target detection via QR and RIF codes, } \\
\text { - } \quad \text { Nocation detection via QR and RIF codes. } \\
\text { Interaction Field Communication (NFC) } \\
\text { - Share with others via social media } \\
\text { - Communicating with others via VOIP } \\
\text { Real-time competition based on a navigation system }\end{array}$ & $\begin{array}{l}\text { Wang et al. (2017), Sánchez et al. (2011), } \\
\text { Jones et al. (2017), Tal (2019), Meishar-Tal } \\
\text { and Ronen (2016), Cesário et al. (2017), } \\
\text { Rosmansyah and Rosyid (2017), Ieiri, } \\
\text { Nakajima, Ayaki and Hishiyama } \\
\text { (2017),Amato et al, (2013), Chiou (2010), } \\
\text { Tal (2019). }\end{array}$ \\
\hline & $\begin{array}{l}\text { Content management and adaptation } \\
\text { - Learning analytics, } \\
\text { User profile } \\
\text { - Content personalization } \\
\text { - Recommendation system }\end{array}$ & \\
\hline $\begin{array}{l}\text { Pervasive games/ Live action role- } \\
\text { playing game }\end{array}$ & No mobile phone application found in the selected data set. & \\
\hline
\end{tabular}

Ghosts is an exploratory and geolocation experimental mobile game designed by Nilsson et al. (2016) that aims to draw attentions to museum artefacts with the help of all knowing "ghosts" that pop-up according to the location in the museum. When playing the game, players are supposed to encounter series of designed ghosts randomly based on their positions and to these ghosts help to find out artefacts in the museum. Therefore, by receiving the feedback about player's real time position, the ghosts help to make sure the players are on the right path to visit the museum, as well as get information on how far they are from the artefacts. In addition, after completion of the game with the support of the ghosts, user are encouraged to share their visiting experiences and achievements through Facebook (Nilsson et al., 2016). This is the type of game that is expected to appear more and more in modern museums. An exploratory and geolocation game that makes use of multiple IoT technologies embedded trough a diverse number of game features and functions.

\section{CONCLUSIONS}

This paper first investigates and identifies the overall use of IoT technologies by serious mobile games aiming at supporting informal learning and improving museum visiting experiences through gamification. Moreover, the paper then studies known types of games, following categorization by Wang and Nunes (2019) and pinpoints which of the identified IoT technologies are used by each of the types of games according to their features and functions. IoT technologies categorization is presented in Table 2 and the study of technologies, features and functions used by each game types is presented in Table 3.

From a theoretical perspective, this meta-analysis study proposes 5 main categories of IoT technologies used by mobile games in the museum context. The study also illustrates features and functions and corresponding use of IoT technologies against its use in each of the mobile games types previously proposed by Wang and Nunes (2019). From the analysis performed, this study proposes the geo-location information function as the crucial facet of mobile serious games to support informal learning in museums. Consequently, this study also concludes that the combination exploratory location games are at the optimal choice of game architecture and design.

From a practical perspective, this study can be used to guide serious game designers on which IoT technologies to select and features to design, according to the types of games they selected and the informal learning they want to support in the museum context in which the games are to be implemented in. The paper also suggests that designers engaging with this type of game should preferentially use location aware architectures supported by geo-information functions.

\section{ACKNOWLEDGEMENT}

The study reported in this paper was partially funded by the Guangdong Social Science Foundation Project No. 2019A1515011260. The paper is part of the contractual agreed output of this project. 


\section{REFERENCES}

Akamca, G. O., Yildirim, R. G., \& Ellez, A. M. (2017). An alternative educational method in early childhood: Museum education. Educational Research and Reviews, 12(14), pp.688-694. doi:10.5897/err2017.3145

Amato, F., Chianese, A., Mazzeo, A., Moscato, V., Picariello, A., \& Piccialli, F. (2013). The talking museum project. Procedia Computer Science, 21, pp. 114-121.

Booth, A., Carroll, C., Papaioannou, D., Sutton, A. and Wong, R., (2009), "Applying findings from a systematic review of workplace based e learning: implications for health information professionals", Health Information \& Libraries Journal, 26(1), pp.4-21.

Byun, H. E., \& Cheverst, K. (2004). Utilizing context history to provide dynamic adaptations. Applied Artificial Intelligence, 18(6), pp.533-548.

Cabrera, J.S., Frutos, H.M., Stoica, A.G., Avouris, N., Dimitriadis, Y., Fiotakis, G. and Liveri, K.D., 2005, September. Mystery in the museum: collaborative learning activities using handheld devices. In Proceedings of the 7th international conference on Human computer interaction with mobile devices \& services. pp. 315-318. ACM.

Ceipidor, U. B., Medaglia, C. M., Perrone, A., De Marsico, M., \& Di Romano, G. (2009, June). A museum mobile game for children using QR-codes. In Proceedings of the 8th international conference on interaction design and children (pp. 282-283). ACM.

Cesário, V., Radeta, M., Matos, S., \& Nisi, V. (2017, October). The Ocean Game: Assessing Children's Engagement and Learning in a Museum Setting Using a Treasure-Hunt Game. In Extended Abstracts Publication of the Annual Symposium on Computer-Human Interaction in Play. pp. 99-109. ACM.

Chiou, C. K., Tseng, J. C., Hwang, G. J., \& Heller, S. (2010). An adaptive navigation support system for conducting context-aware ubiquitous learning in museums. Computers \& Education, 55(2), pp.834-845.

De Rijcke, S. and Beaulieu, A., 2011. Image as interface: consequences for users of museum knowledge. library trends, 59(4), pp.663-685.

Dey, A. K. (2001). Understanding and using context. Personal and Ubiquitous Computing, 5(1), pp. 4-7.

Dix, A., Rodden, T., Davies, N., Trevor, J., Friday, A., \& Palfreyman, K. (2000). Exploiting space and location as a design framework for interactive mobile systems. ACM Transactions on Computer-Human Interaction (TOCHI), 7(3), pp.285-321.

Efird, R. (2014). Learning places and 'little volunteers': an assessment of place- and community-based education in China. Environmental education research, 21(8), pp.1143-1154. doi:10.1080/13504622.2014.976607

Eshach, H. (2006). Bridging In-school and Out-of-school Learning: Formal, Non-Formal, and Informal Education. Journal of Science Education and Technology, 16(2), pp. 171-190.

Falk, J.H., \& Dierking, L.D. (2008). Enhancing visitor interaction. In L. Tallon \& K. Walker (Eds.), Digital technologies and the museum experience: handheld guides and other media (pp. 19-33). Lanham: Altamira Press.

Fitz-Walter, Z., \& Tjondronegoro, D. W. (2011, September). Exploring the opportunities and challenges of using mobile sensing for gamification and achievements. In UbiComp 11: Proceedings of the 2011 ACM Conference on Ubiquitous Computing. pp. 1-5. ACM Press.

Gellersen, H. W., Schmidt, A., \& Beigl, M. (2002). Multi-sensor context-awareness in mobile devices and smart artefacts. Mobile Networks and Applications, 7(3), pp.341-351.

Greenspan, B., \& Whitson, J. R. (2013, May). Whether to play or preserve the past?: Creating The Forgotten Worker Quest. In FDG pp. 298-305.

Hazas, M., Scott, J., \& Krumm, J. (2004). Location-aware computing comes of age. Computer, 37(2), pp.95-97.

Heumer $^{1}$, G., Gommlich¹, F., Jung1, B., \& Müller, A. (2007). Via Mineralia-a pervasive museum exploration game.

Hong, J. Y., Suh, E. H., \& Kim, S. J. (2009). Context-aware systems: A literature review and classification. Expert Systems with applications, 36(4), pp. 8509-8522.

Hsu, T. Y., Liang, H., Chiou, C. K., \& Tseng, J. C. (2018). CoboChild: a blended mobile game-based learning service for children in museum contexts. Data Technologies and Applications, 52(3), 294-312.

Hughes, K., \& Moscardo, G. (2017). Connecting with new audiences: Exploring the impact of mobile communication devices on the experiences of young adults in museums. Visitor Studies, 20(1), pp.33-55.

Hwang, G. J., Wu, C. H., Tseng, J. C., \& Huang, I. (2011). Development of a ubiquitous learning platform based on a real-time help-seeking mechanism. British Journal of Educational Technology, 42(6), pp.992-1002.

Ieiri, Y., Nakajima, Y., Ayaki, R., \& Hishiyama, R. (2017, July). A Walk Rally Application to Motivate Users to Visit Potential Sightseeing Resources. In 2017 IEEE 41st Annual Computer Software and Applications Conference (COMPSAC) 2, pp. 637-642). IEEE.

Jesson, J., Mstheson, L., \& Lacey, F. M. (2011). Doing Your Literature Review: SAGE. 
Jones, C. E., Liapis, A., Lykourentzou, I., \& Guido, D. (2017, May). Board game prototyping to co-design a better location-based digital game. In Proceedings of the 2017 CHI Conference Extended Abstracts on Human Factors in Computing Systems.pp. 1055-1064. ACM.

Kang, C., Anderson, D., \& Wu, X. (2009). Chinese perceptions of the interface between school and museum education. Cultural Studies of Science Education, 5(3), pp.665-684. doi:10.1007/s11422-009-9197-2

Kim, S. Y., So, H. J., Kwon, S., Oh, S., Park, K., Ko, M., \& Oh, G. (2015, July). Towards designing a mobile social learning application with meaningful gamification strategies. In 2015 IEEE 15th International Conference on Advanced Learning Technologies. pp. 170-174. IEEE.

Kirci, P., \& Kahraman, M. O. (2015, May). Game based education with android mobile devices. In 2015 6th international conference on modeling, simulation, and applied optimization (ICMSAO). pp. 1-4. IEEE.

Krassmann, A. L., Falcade, A., Bernardi, G., \& Medina, R. D. (2017). Exploring Student's Motivational Aspects by Developing and Applying a Ubiquitous Digital Serious Game Approach. Journal of Creative Education, 8(3), pp.405.

Kristianto, K., Dela, K., \& Santoso, H. (2018). Implementation of Gamification to Improve Learning in Museum.

Kuflik, T., Stock, O., Zancanaro, M., Gorfinkel, A., Jbara, S., Kats, S., ... \& Kashtan, N. (2011). A visitor's guide in an active museum: Presentations, communications, and reflection. Journal on Computing and Cultural Heritage (JOCCH), 3(3), pp.11.

Laine, T. H., Sedano, C. I., Vinni, M., \& Sutinen, E. (2007, October). Engagement, motivation and inspiration: the SciMyst framework in museums. In Proc. of the Fourth Conference on New Exploratory Technologies.

Machado, M. (2016, July). Participatory Culture and Digital Concept at the Favela Museum, Rio de Janeiro, Brazil. In 3rd European Conference on Social M di R h Media Research EM Normandie, Caen, France (p. 180).

Marcus, A. (2015). The Story Machine: Combining Information Design/Visualization with Persuasion Design to Change Family-Story Sharing Behavior. In Mobile Persuasion Design. pp. 163-260. Springer, London.

Meishar-Tal, H., \& Ronen, M. (2016). Experiencing a Mobile Game and Its Impact on Teachers' Attitudes towards Mobile Learning. International Association for Development of the Information Society.

Miyata, H., \& Kozuki, N. (2008, July). Mobile \& Collaborative Learning Development by a Concept of "Mobile-As-Participation-Platform". In ITC-CSCC: International Technical Conference on Circuits Systems, Computers and Communications. pp. 829-832.

Nilsson, T., Blackwell, A. F., Hogsden, C., \& Scruton, D. (2016). Ghosts! A location-based bluetooth LE mobile game for museum exploration. In Mapping the Digital: Cultures and Territories of Play. pp. 129-138. Brill.

Nunes, J. M., Kainwal, S., \& Arif, M. (2017). Knowledge Management practices in Higher Education Institutions: a Systematic literature Review. Creative Commons Attribution, 4, pp.1-16.

Nunes, M., McPherson, M., Annansingh, F., Bashir, I., \& Patterson, D. (2009). The use of elearning in the workplace: a systematic literature review. Impact: Journal of Applied Research in Workplace E-learning, 1(1), pp.97-112.

Radeta, M., Cesario, V., Matos, S., \& Nisi, V. (2017, November). Gaming versus storytelling: understanding children's interactive experiences in a museum setting. In International Conference on Interactive Digital Storytelling (pp. 163-178). Springer, Cham.

Rosmansyah, Y., \& Rosyid, M. R. (2017, October). Mobile learning with gamification for Alquran memorization. In 2017 International Conference on Information Technology Systems and Innovation (ICITSI) pp. 378-383. IEEE.

Rowe, J. P., Lobene, E. V., Mott, B. W., \& Lester, J. C. (2014). Play in the museum: Designing game-based learning environments for informal education settings. In $F D G$.

Rubino, I., Barberis, C., Xhembulla, J., \& Malnati, G. (2015). Integrating a location-based mobile game in the museum visit: Evaluating visitors' behaviour and learning. Journal on Computing and Cultural Heritage (JOCCH), 8(3), pp.15.

Russo, A., Watkins, J., \& Groundwater-Smith, S. (2009). The impact of social media on informal learning in museums. Educational Media International, 46(2), pp.153-166.

Sánchez, M., García, O., Alonso, R. S., Guevara, F., Sancho, D., \& Bajo, J. (2011). ARTIZT: applying ambient intelligence to a museum guide scenario. In Ambient Intelligence-Software and Applications (pp. 173-180). Springer, Berlin, Heidelberg.

Saunders, M., Lewis, P. and Thornhill, A., (2016), Research methods for business students, 7/ê̂, Pearson Education limited, Italy.

Sedano, C. I., Sutinen, E., Vinni, M., \& Laine, T. H. (2012). Designing hypercontextualized games: a case study with LieksaMyst. Journal of Educational Technology \& Society, 15(2), 257-270.

Stylianidis, P. (2015, November). Mobile learning: open topics, concept and design of a learning framework. In 2015 International Conference on Interactive Mobile Communication Technologies and Learning (IMCL) pp. 421-424. IEEE.

Su, C. H., \& Cheng, C. H. (2013). A mobile game-based insect learning system for improving the learning achievements. Procedia-Social and Behavioral Sciences, 103, pp. 42-50. 
Sweetser, P., \& Wyeth, P. (2005). GameFlow: a model for evaluating player enjoyment in games. Computers in Entertainment (CIE), 3(3), pp.3-3.

Tal, H. M. (2019). Strategies for Developing Mobile Location-Based Learning Activities by Teachers. In Mobile Technologies in Educational Organizations. pp. 85-95. IGI Global.

Terreni, L. (2015). Young children's learning in art museums: a review of New Zealand and international literature. European Early Childhood Education Research Journal, 23(5), pp.720-742. doi:10.1080/1350293x.2015.1104049

Wallace, M. and Wray, A. (2011), ìCritical reading and writing for postgraduates (2nd ed.)î, Sage.

Wang, L., Gunasti, K., Gopal, R., Shankar, R., \& Pancras, J. (2017, January). The Impact of Gamification on Word-ofMouth Effectiveness: Evidence from Foursquare. In Proceedings of the 50th Hawaii International Conference on System Sciences.

Wang, M. and Nunes, M.B., (2018). Identification of Serious Games for Museum's Educational Roles: A Critical Literature Review. In M. Macedo \& P.Kommers(Eds.). Proceedings of international conference on ICT society and Human Beings, Madrid, Spain, pp. 131-140.

Wang, M., \& Nunes, M. B. (2019). Matching serious games with museum's educational roles: smart education in practice. Journal of Interactive Technology and Smart Education. 6(4), pp. 319-342.

Want, R., \& Schilit, B. (2001). Expanding the horizons of location-aware computing. Computer, 34(8), pp.31-34.

Washburn, W. E. (1975). Do museums educate? Curator: The Museum Journal, 18(3), pp.211-218.

Williams, B. L. (1996). An Examination of Art Museum Education Practices Since 1984. Journal of National Art Education Association, 38(1), pp.34-49. 